\title{
ON THE INFRA-RED SPECTRA OF THE ALKALIES. ${ }^{1}$
}

By Benjamin W. Snow.

\section{INTRODUCTION.}

UR knowledge of the infra-red portion of the solar spectrum is confined almost entirely to investigations which have been made during the last fifty years. As early as the year I 840, Sir John Herschel ${ }^{2}$ succeeded in showing an uneven distribution of energy in that part of the solar spectrum lying beyond the red, by allowing the spectrum of the sun's rays to fall upon a paper moistened with alcohol, and observing that at certain places in the invisible spectrum the paper dried more rapidly than at others. From this he concluded that the continuous solar spectrum is crossed at intervals by cold bands.

Later investigators have employed a variety of methods to confirm these results. Draper, ${ }^{3}$ the two Becquerels ${ }^{4}$ and Lommel ${ }^{5}$ by means of phosphorescent plates, Fizeau and Foucault ${ }^{6}$ by using a thermometer, Lamansky, ${ }^{7}$ Mouton, ${ }^{8}$ and Dessains ${ }^{9}$ with the thermopile, Abney ${ }^{10}$ by photographic methods, and finally

1 From Wiedemann's Annalen Bd. 47 (communicated by the author).

2 Sir Fohn Herschel, Proc. Roy. Soc., p. 209, I840. Phil. Mag., r6, p. 331, I840.

${ }^{3}$ Draper, Phil. Mag., 24, p. 456, I842; I I, p. 157, I88I.

4 E. Becquerel, Compt. rend., 69, p. 999, 1869; 77, p. 302, 1873. H. Becquerel, Compt. rend., 96, p. 123, 1883; 99, p. 417, 1884. Ann. de Chim. et de Phys., 30, p. 33, I 883 .

5 Lommel, Wied. Ann., 40, p. 681, i $890 ; 40$, p. 687, 1890.

${ }^{6}$ Fizeau and Foucault, Compt. rend., 25, p. 449, 1847.

7 Lamansky, Monatsber. der k. Acad. d. Wiss. zu Berlin, p. 638, 187r. Pogg. Ann., I46, p. 207, 1872. Phil. Mag., 43, p. 282, 1872.

8 Mouton, Compt. rend., 89, p. 298, 1879.

${ }^{9}$ Dessains, Compt. ren $1 ., 95$, p. 435, I 882.

1) Abney, Phil. Trans., II., p. 653, I880; p. 457, 1886. 
Langley ${ }^{1}$ with the aid of the bolometer, have not only verified the three bands first suspected by Herschel, but have found many new ones, and have given to each its respective wavelength.

Captain Abney appears to have been the first person who succeeded in studying the infra-red spectra of the metals. In a paper ${ }^{2}$ published in 1879 , he stated that the emissive spectrum of lithium contains an infra-red line which coincides in position with a line previously discovered by him in the absorption spectrum of this metal. Later experiments ${ }^{3}$ showed that sodium also, when burned in the electric arc, has two infra-red lines having wave-lengths $\lambda=.8187 \mu$ and $\lambda=.8199 \mu$ respectively. The intensity of these lines was estimated at 3 , the intensity of the D lines being taken as Io.

Apparently without a knowledge of Abney's work, H. Becquerel found, during the next four years, that many other metals besides sodium and lithium have interesting spectra in the infra-red. The two sodium lines discovered by Abney were again determined by Becquerel, and a third line of still greater wave-length observed.

His first method ${ }^{4}$ for determining the wave-lengths of these lines consisted in projecting upon the slit of the spectrometer a real image of the arc in which the metals were burned, and receiving upon a phosphorescent plate the spectrum produced by a calibrated prism. These experiments were repeated a year later, ${ }^{5}$ when the prism producing the spectra was replaced by a Rutherford grating. Mention will again be made of these researches of Becquerel, and a comparison drawn between his results and those now under consideration, when the latter are discussed at the close of the present paper. .

From conclusions reached in a recent series of investigations, Kayser and Runge ${ }^{6}$ have shown, in an article "Ueber die Spectren

1 Langley, Report of the Mt. Whitney Expedition, p. 131, 1884. Phil. Mag. (5), 26, p. 5 I I, 1888 .

2 Abney, Phil. Mag. (5), 7, p. 316, 1879.

3 Abney, Proc. Roy. Soc., 32, p. 443, i 38 i.

${ }^{4}$ H. Becquerel, Compt. rend., 97, p. 71, 1883. Ann. de Chim. et de Phys., 30, p. 45,1883 .

5 H. Becquerel, Compt. rend., 99, p. 374, 1884 .

${ }^{6}$ Kayser und Runge, Wied. Ann., 41, p. 306, 189o. 
der Alkalien," that the wave-lengths of the spectral lines of the metals belonging to this group bear to each other a mathematical relation, and may be represented by a formula. The constants of these formulæ, being determined by measurements made in the visible and ultra-violet portions of the spectrum, can rightfully be used, strictly speaking, only in those regions for which they were found. Since, however, these authors ascribe to their formulæ a general validity, and inasmuch as the wave-lengths of the infra-red lines obtained from them by extrapolation do not in all cases coincide with the results of previous observers, it appears to the present writer not altogether without interest to submit anew to a careful study the heat spectrum of the alkaline metals.

\section{EXPERIMENTAL METHODS AND APPARATUS.}

\section{The Bolometer.}

For a considerable period the bolometer has proven itself to be the best means of studying spectra in the infra-red. This instrument in the perfected state, to which it has been developed by such men as Langley, Angström, Robert von Helmholtz, and Rubens, fulfilled the conditions necessary to the solution of the present problem. It has been shown that resistances sensitive to temperature can be made so narrow that even in a very pure spectrum they do not exceed in width the breadth of the spectral lines, and that the delicacy of this method far exceeds that of photographic processes.

After a long series of experiments, platinum was chosen as the material for the bolometer resistances. This metal, it is true, is never to be obtained in such a degree of purity ${ }^{1}$ that its temperature coefficient equals that of silver, copper, tin, or iron, but it possesses, on the other hand, in its durability and convenience of working, such superior advantages over all other materials, that the loss in sensitiveness, conditioned by its smaller temperature coefficient, is more than compensated.

Professor Edward L. Nichols, of Cornell University, very kindly supplied me with a quantity of platinum wire drawn in silver,

1 The smallest traces of iridium seriously affect the result. 
from the workshops of W. and L. E. Gurley, of Troy, N.Y. While still in its covering of silver, this fine platinum wire, only $.005 \mathrm{~mm}$. in diameter, was hammered flat on a polished anvil, after which the silver was dissolved with nitric acid from the platinum ribbon within. The platinum strip so formed had a breadth of $.05 \mathrm{~mm}$. From this and its slightly increased length due to the hammering its thickness was calculated to be $.00036 \mathrm{~mm}$.

Two platinum threads prepared in this way were fastened side by side with shellac upon a little frame of mica. The frame itself was then fastened in such a way in a circular wooden case that one of the strips, which had previously been blackened by smoking in a turpentine flame, came directly opposite a rectangular opening in the cover, and was thus exposed to all radiations, while the other was completely protected by the walls of the case. Corresponding to the size of the opening in the diaphragm of the casing $(3 \times 7 \mathrm{~mm}$.), the platinum threads, when in position, had a length of $7 \mathrm{~mm}$.

Figure I represents the arrangement of the interior of the little wooden box. Copper wires, soldered to the ends of the platinum threads, connected these strips with the three brass sleeves $A$, $B, C$. These sleeves were then slipped over three corresponding rods in the bolometer sheathing or holder, and thus served to support the little case in its place, and at the same time to afford electrical contact with the interior. The points $A$ and $C$ led to the battery, while $B$ formed one point of contact with the galvanometer.

The two resistances were made as nearly alike as possible, and each measured about $75 \mathrm{ohms}$. The other two resistances in the Wheatstone's bridge were made of fine German silver wire, and wound non-inductively upon corks.

It was soon found that the task of balancing the Wheatstone's bridge would be made much lighter if small changes could be introduced at pleasure in the relation of the resistances forming the four arms. To attain this result, the two branches of the bridge last named, made of German silver, were connected by a German silver wire $50 \mathrm{~cm}$. long and $.5 \mathrm{~mm}$. in diameter, upon which rested a sliding contact. 
A short trial, however, soon proved that a simple displacement of this point of contact was not well adapted to a rapid and accurate balancing of the bridge. With the exceedingly high degree of sensitiveness of the galvanometer employed, a change in the position of the sliding contact of a fraction of a millimeter caused a throw of the galvanometer needle of several meters, a circumstance which rendered the manipulation of the apparatus exceedingly difficult. There was accordingly placed upon the

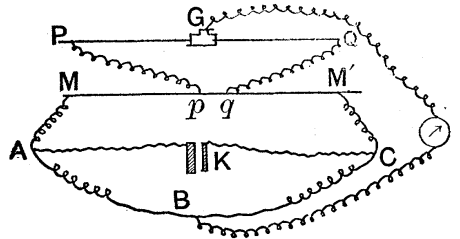

Fig. 2. bridge wire $M M^{\prime}$ (Fig. 2) a second movable contact, and both of these sliding contacts, $p$ and $q$, were joined with the ends, $P$ and $Q$, of a straight platinum wire, upon which slipped a small glass T-shaped tube filled with mercury. The latter formed the other terminal of the galvanometer circuit. $A B$ and $B C$ were the two platinum resistances in the circular case, and $A M$ and $C M^{\prime}$ the other two resistances, joined by the bridge wire $M M^{\prime}$. The battery connection was made at points $A$ and $C$.

With this apparatus, the balancing of the bridge was effected in the following manner: The sliding contacts, $p$ and $q$, were first placed in such a position that the point which had the same potential as the point $B$ should fall between them. The distance between these movable contacts was then made as small as possible. Since the resistance of the connecting wires, $p P$ and $q Q$, was negligible in comparison with that of the bridge wire, there existed the same fall of potential between the points $P$ and $Q$ as between the points $p$ and $q$. It was possibie, therefore, with this arrangement to vary at will the sensitiveness of the apparatus within wide limits. The approximate adjustment was made by displacing $p$ and $q$, and the final balancing accomplished by slipping th - tube $G$ along the wire $P Q$.

To determine the sensitiveness of the instrument to thermal changes, a method was employed which has been described by Rubens and Ritter. ${ }^{1}$

${ }^{1}$ Rubens and Ritter, Wied. Ann., 40, p. 62, 1890. 
In parallel arc with one of the bolometer resistances of 75 ohms was placed a shunt of 1000 ohms, and around two ohms of this resistance was laid a second shunt of roo ohms (see Fig. 3). In the latter circuit was placed a key. Opening or closing this key changed the resistance of the first shunt circuit by nearly $\frac{2}{1000} \cdot \frac{2}{100}$ of its former amount, whereby the entire resistance of the arm of the bolometer suffered a change amounting nearly to $\frac{75}{1000} \cdot \frac{2}{1000} \cdot \frac{2}{100}$. The temperature coefficient of the platinum employed being .0O30, the sensi-

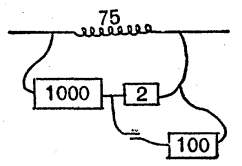

Fig. 3. tiveness to temperature, as calculated from the above figures and the throw $\alpha$, of the galvanometer, was found to be

$$
k=\frac{75}{1000} \cdot \frac{2}{1000} \cdot \frac{2}{100} \cdot \frac{\mathrm{I}}{.0030 \alpha} .
$$

With the degree of astaticism used throughout the experiments, $\alpha$ was about $\mathrm{r} 30 \mathrm{~mm}$. The constant $k$ was therefore found to be

$$
k=\frac{1}{130000^{\circ}} \mathrm{C} \text {. }
$$

With this sensitiveness, a standard candle at a distance of I $\mathrm{m}$. produced a deflection of $150 \mathrm{~mm}$.

\section{The Galvanometer.}

It is well known that it is not difficult to make a bolometer sufficiently delicate to indicate minute differences of temperature, provided the surface exposed to the radiation may be made sufficiently large. If, however, it is desired, as in the present investigation, to discern fine lines in the spectrum by the heat which they emit, it is necessary to use for the purpose a linear bolometer in which the surface upon which the radiations fall comprises only a small fraction of a square millimeter. The illuminated filament of platinum in the bolometer already described, being $7 \mathrm{~mm}$. in length and $.05 \mathrm{~mm}$. in breadth, exposed a surface of about $\frac{1}{3}$ sq. $\mathrm{mm}$.

Since the sensitiveness of a bolometer is nearly proportional to the square root of its available surface, it was necessary to use a galvanometer of the highest degree of delicacy in order that the 
deflections might be sufficiently large to render the observations trustworthy. After many fruitless attempts to make use of the instruments already at hand, it was decided to construct one which would have the required degree of sensitiveness. Since a delicate galvanometer is often required in other lines of work, it may be not altogether without profit to give the details of its construction.

In order to obtain the highest efficiency from the galvanometer, it is necessary to use an astatic system which combines the smallest possible moment of inertia with the greatest strength and uniformity of magnetization. These two purposes were accomplished in the following arrangement.

After the model of Lord Kelvin's instruments, the magnets consisted of twelve little steel bars, 3 and $4 \mathrm{~mm}$. long, fastened with shellac to the ends of an exceedingly fine, thinwalled capillary tube, three magnets being on the front side of the tube, and three on the back, at each end. A very small watch spring furnished the steel from which the magnets were made. This was first heated in potassium ferrocyanide and then hardened in mercury. Half-way between the two systems of magnets, and resting in its little stirrup of tissue paper, was placed a small mirror $5 \mathrm{~mm}$. in diameter and . $14 \mathrm{~mm}$. thick.

To make a mirror sufficiently accurate for the purpose, about fifty microscope cover-glasses were cut in pieces Fig. 4. $5 \mathrm{~mm}$. square, cleaned, and laid upon a piece of plane glass. These little plates were then viewed by the monochromatic light of the sodium flame, and the interference figures observed which were produced in the enclosed layer of air. It was found possible to tell by the form and position of these interference bands which pieces were adapted to the manufacture of mirrors.

Such interference figures are in general elliptically or hyperbolically curved, thus showing that the surface under examination has two noticeably different radii of curvature. It is clear that such surfaces can give no perfect images, inasmuch as an astigmatic eye would be necessary to see objects in their natural form.

If, on the other hand, the interference bands form systems 
of parallel straight lines or concentric rings, we have to deal with plane surfaces or surfaces of revolution, which are, in most cases, capable of giving good definition.

A number of these pieces were thus selected from the rest, silvered, and examined with a telescope and scale. Finally, that one which seemed the most nearly perfect was fastened, as already described, upon the needle of the galvanometer.

The weight of the entire needle, including the twelve magnets, the mirror, holder, and connecting rod, was about 80 milligrams.

As a suspension for the needle, an exceedingly fine quartz fiber, $40 \mathrm{~cm}$. long, was employed, instead of one of the fibers IO c.m. long which Professor C. V. Boys very kindly sent for the purpose. It seemed at that time that the torsion of the latter would be too great when compared with the very feeble directive force employed. This was, however, an erroneous belief, as was abundantly proven by later experiments.

Next to the construction of the needle, the greatest care was given to the design of the coils. Particularly did it seem of the greatest moment to make the best possible use of the space available for winding the wire. With this in view, several points were to be considered. The end to be attained demanded that the coils be given such a form that a current of a certain strength, and meeting within the coil the smallest possible resistance, should exert upon the needle the maximum magnetic effect. A simple consideration shows ${ }^{1}$ that the space to be filled with wire must be given such a form that its surface will be bounded by the magnetic lines of force due to the current. The effectiveness will be still further increased if the wire is brought as close as possible to the needle.

In order to conform to these several conditions, a device was employed by which it was possible completely to dispense with the spool or thimble upon which the wire is usually wound, and at the same time to give the coils approximately the desired shape.

These ends were accomplished by providing a brass block,

${ }_{1}^{1}$ Maxwell, Electricity and Iíagnetism, second ed., Art. 717; Ayrton, Mather and Sumpner, Phil. Mag. (5), 30, p. 63, 1890. 
acefdb (shown in axial section in Fig. 5), the cylindrical part being $3 \mathrm{~cm}$. in diameter, and the conical end at $a b$ being $6 \mathrm{~mm}$. in diameter. Upon this block was fastened, by the set screw

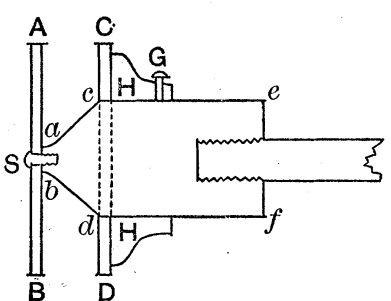

Fig, 5 . $G$, the brass collar $H$. Against this ring as a shoulder rested the brass plate $C D$, having in its center a circular opening which allowed the plate to be supported upon the cylindrical part of the block. At the conical end, $a b$, a screw $S$ held in place the plate $A B$. These two plates were then situated I $5 \mathrm{~mm}$. apart.

The space enclosed between this form and the two plates was then wound with wire. The part as far as $c d$ contained I Ioo turns of wire $.25 \mathrm{~mm}$. in diameter, and the remaining space was filled with 700 turns of wire $.5 \mathrm{~mm}$. in diameter.

The wire, while still in position between the plates upon the brass form, was then placed in a bath of melted paraffine, in which it remained until thoroughly heated. The vessel with all its contents was next placed under the receiver of an air-pump and the air withdrawn. As the vacuum became higher, the air which had been confined in the silk covering of the wire escaped, while at the same time the moisture was vaporized which had found its way, during the process of winding, to the insulating material around the wire. As soon as the atmosphere was again admitted to the receiver, the increased pressure caused the paraffine to fill the smallest interstices between the wire, so that, when cold, the whole formed a compact mass easy to handle.

The superfluous paraffine was then cut away, the screws $S$ and $G$ removed, and the plate $A B$ quickly warmed in the flame of the Bunsen burner. Before the heat had been communicated to the remainder of the material, the plate slipped away from the wire, which still remained imbedded in the paraffine. The blast-lamp was then directed against the brass block, which in like manner became hot, and was removed without injury to the wire.

The coil in this form, held together as it was only by the 
paraffine, and supported solely by the rear plate $C D$, was now ready for use in the construction of the galvanometer.

Two coils made in this way were mounted in a rectangular case directly below two similar coils (see Fig. 6), and so placed that the surfaces which, in the process of construction, had been formed by the plate $A B$, were now situated opposite each other and $\mathbf{I}$ $\mathrm{mm}$. apart. The front and the rear sides of the case, upon which the coils were mounted, were made of wood, the other two sides being formed simply of narrow panes of glass. It was easy, there-

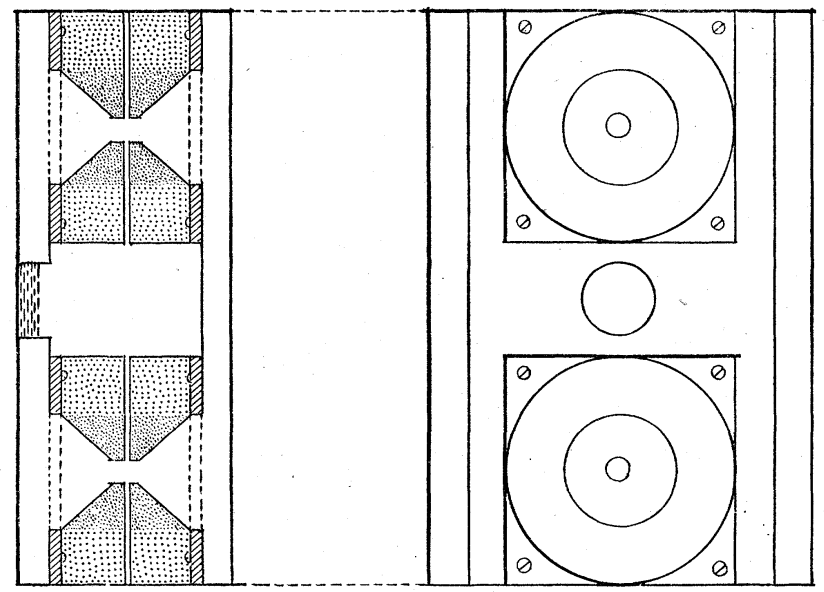

Fig. 6.

fore, to examine from the outside the condition of the interior, so that any lack of freedom in the suspended system could readily be corrected. Binding-screws, placed upon the front wall of the galvanometer case, formed the means of electrical contact with the coils within. That part of the wall which supported the two front coils was movable, and could be taken out and replaced at pleasure. The interior was thus at all times accessible.

The description of the galvanometer will now be complete when mention is made of the fact that the instrument was placed upon a base, provided in the usual way with three levelling-screws, and that upon the upper part of the case was secured a glass tube $40 \mathrm{~cm}$. long, at the upper end of which was fastened the quartz thread for the suspension. 
The characteristic constants of this galvanometer were as follows: When the coils were connected in series, the current traversed 7200 turns of wire, of which the total resistance was I 40 ohms. When the controlling magnet near the instrument was in such a position that a double vibration of the needle was performed in 20 seconds, I $\mathrm{mm}$. deflection on the scale $3 \mathrm{~m}$. away indicated a current of $1.5 \times 10^{-11}$ ampères. In conducting the final experiments, however, it was found that a sensitiveness less than this was amply sufficient, and the time of vibration was accordingly reduced to 7 seconds. Even then its delicacy was notably higher than that of the commercial instruments.

\section{The Calibration of the Prism.}

A prism of medium silicate-flint glass of high dispersive power, mounted upon a spectrometer from the workshops of Schmidt and Haensch, formed the apparatus with which the spectra were studied. The prism was preferred for this purpose to a diffraction grating, because the superposition of the spectra produced by the latter rendered difficult the detection and identification of lines in the infra-red, and further because the energy in the prismatic spectrum is far more intense than is developed in any one of the numerous diffraction spectra.

After the method recently described ${ }^{1}$ by Rubens, a number of calibrations of the prism were made, in all of which Dr. Rubens himself kindly assisted. The several experiments yielded results agreeing well among themselves, from which the dependence of the wave-length of the infra-red rays upon the angle of deviation could be determined within about five parts in a thousand.

The results of the first calibration are shown graphically in Fig. I, Plate I. This figure represents the energy spectrum of the source of light, crossed by the heavy interference bands. The double thickness of the layer of air producing the interference, multiplied by the cosine of the angle of incidence $i$ of the rays, gave $k=6.677 \mu$, as was determined from observations in the visible spectrum. The first infra-red interference band was

\footnotetext{
1 Rubens, Wied. Ann., 45, p. 238, 1892.
} 
of the 9th order, from which, accordingly, for this band, $n=9$. With the aid of these constants and the observed position of the maxima and minima, corrected before using by the method of envelopes given by Rubens, were calculated the values of the wave-lengths corresponding to the following angles of deviation $\phi$.

TABLE I.

\begin{tabular}{|c|c|c|c|c|c|}
\hline Name. & $\phi$ & $\lambda$ & NAME. & $\phi$ & $\lambda$ \\
\hline$H_{\gamma}$ & $50^{\circ} 51 \frac{1}{2}^{\prime}$ & $0.434 \mu$ & $b_{3}$ & $46^{\circ} 49^{\prime}$ & $1.026 \mu$ \\
\hline$F$ & $49^{\circ} 46 \frac{1}{2}^{\prime}$ & 0.486 “ & $a_{4}$ & $\quad 39 \frac{1}{2}^{\prime}$ & 1.111 “ \\
\hline$D$ & $48^{\circ} 31^{1 \prime}$ & 0.589 “ & $b_{4}$ & $30^{\prime}$ & 1.214 “ \\
\hline$C$ & $2 \frac{1}{2}$ & 0.656 “ & $a_{5}$ & $20 \frac{1}{2} !$ & $1.336 “$ \\
\hline$a_{1}$ & $47^{\circ} 37^{\prime}$ & 0.753 “ & $b_{5}$ & $9^{\prime}$ & 1.482 “ \\
\hline$b_{1}$ & $26 \frac{1}{2}{ }^{\prime}$ & $0.786 “$ & $a_{6}$ & $45^{\circ} 55 \frac{1}{2}{ }^{\prime}$ & 1.669 “ \\
\hline$a_{2}$ & $16^{\prime}$ & 0.834 “ & $b_{6}$ & $37 \frac{1}{2}^{\prime}$ & 1.906 “ \\
\hline$b_{2}$ & $7^{\prime}$ & 0.889 “ & $a_{7}$ & $14 \frac{1}{2}^{\prime}$ & 2.225 “ \\
\hline$a_{3}$ & $46^{\circ} 58^{\prime}$ & 0.952 “ & $b_{7}$ & $44^{\circ} 45 \frac{1}{2}^{\prime}$ & 2.668 “ \\
\hline
\end{tabular}

Two other series of observations were conducted in precisely the same way, except that the thickness of the layer of air which caused the interference was changed, so there were obtained in all three entirely independent calibrations of the prism. The wave-lengths corresponding to a series of equidistant deviations of the bolometer arm were determined by interpolation from each of these curves. In Table II. are contained the results which were thus obtained. The first column contains the angle $\phi$, the following three the wave-lengths taken from the respective curves of dispersion, and the last the mean of these results. From the values contained in the last column, and the corresponding angles of dispersion, the curve of dispersion (Fig. 2, Plate I.) was constructed. This curve was used in all the determinations of wave-length which follow.

Since the dispersion in the visible spectrum was very great, this region was calibrated separately by reference to a large number of Fraunhofer lines, and a curve of dispersion for this portion of the spectrum was plotted on a larger scale than that used for the infra-red. 
TABLE II.

\begin{tabular}{|c|c|c|c|c|}
\hline$\phi$ & I. & II. & III. & MEAN $\lambda$. \\
\hline $50^{\circ} 51^{\prime}$ & $0.434 \mu$ & $0.434 \mu$ & $0.434 \mu$ & $0.434 \mu$ \\
\hline $49^{\circ} 46^{\prime}$ & $0.486 “$ & 0.486 “ & $0.486 “$ & 0.486 “ \\
\hline $48^{\circ} 31^{\prime} \frac{1}{2}^{\prime}$ & 0.589 “ & 0.589 “ & 0.589 “ & 0.589 “ \\
\hline $2^{\prime}$ & 0.656 " & 0.656 “ & 0.656 “ & 0.656 “ \\
\hline $47^{\circ} 50^{\prime}$ & 0.695 “ & 0.690 “ & 0.686 “ & 0.690 “ \\
\hline $40^{\prime}$ & 0.729 “ & 0.722 “ & 0.723 “ & 0.725 “ \\
\hline $30^{\prime}$ & 0.767 “ & 0.761 “ & 0.766 “ & 0.765 “ \\
\hline $20^{\prime}$ & 0.813 “ & 0.809 “ & 0.814 “ & 0.812 “ \\
\hline $10^{\prime}$ & 0.872 “ & 0.864 “ & 0.872 “ & 0.869 “ \\
\hline $0^{\prime}$ & 0.940 “ & 0.937 “ & 0.945 “ & 0.941 " \\
\hline $46^{\circ} 50^{\prime}$ & 1.018 " & 1.014 “ & 1.022 “ & 1.018 “ \\
\hline $40^{\prime}$ & 1.109 “ & 1.104 “ & 1.112 " & $1.108 “$ \\
\hline $30^{\prime}$ & 1.215 “ & 1.218 “ & 1.222 " & 1.218 “ \\
\hline $20^{\prime}$ & 1.339 “ & 1.347 " & 1.348 " & 1.335 “ \\
\hline $10^{\prime}$ & 1.473 “ & 1.481 “ & 1.482 " & 1.479 “ \\
\hline $0^{\prime}$ & 1.611 " & $1.610 " ،$ & 1.617 " & 1.613 " \\
\hline $45^{\circ} 50^{\prime}$ & $1.746 “$ & 1.743 “ & 1.751 “ & 1.747 “ \\
\hline $40^{\prime}$ & 1.881 “ & 1.872 “ & 1.887 “ & 1.880 “ \\
\hline $30^{\prime}$ & 2.017 “ & 2.004 " & 2.022 “ & 2.014 “ \\
\hline
\end{tabular}

4. On the Manipulation of the Bolometer.

Before mention is made of the details and results of the experiments themselves, a few words of suggestion should not be omitted which may be found useful in the manipulation of a bolometer.

As already stated in an earlier part of the paper, two arms of the bolometer were made of German silver, and the other two of platinum. Of the two latter branches, the one which was exposed to the radiations had been coated with lamp-black by smoking in a flame, and thus through this exposure to heat its temperature coefficient had to some extent been changed. As a result of this slight difference in the condition of the two arms, a perfect equilibrium could be maintained within the Wheatstone's bridge at a single temperature only. If, accordingly, the temperature of the room rose or fell, a drift of the needle in the one direction or the other became at once perceptible. 
The disturbing effects of this drift were almost completely avoided if, some time before the observations were to begin, the precaution was taken to close the circuit through the bolometer, to light the burners illuminating the galvanometer scale, ${ }^{1}$ to set in operation the electric lamp, the purpose of which will be described later, and at the same time to open the door of the room, in order that as regards all thermal changes an equilibrium might be established.

Even with the utmost care it was impossible to entirely eliminate the drift of the needle, but it was easily possible to make this disturbance so small that for an interval of many minutes the cross-hairs remained upon the same division of the scale. So sensitive was the apparatus to any changes in the temperature of the room, that it was invariably found possible to reverse the direction of the slow, ever-present drift simply by increasing or decreasing, often by not more than $\mathrm{I} \mathrm{cm}$., the amount by which the door stood open. This simple but effectual regulation frequently made it an easy matter to conduct the entire series of observations, lasting three hours, without altering the position of the sliding contact $G$ (Fig. 2) in the Wheatstone's bridge.

The effect of the feeble drift which even this expedient failed to remove was still further reduced by observing the zero point of the needle after the throw as well as before, and taking the mean as the true zero. By this method of observation a uniform drift would be wholly without influence upon the result.

In the entire series of measurements it was not the final deflection, but the first throw of the needle, which was observed. There was secured by this means not only a saving of no inconsiderable amount of time, but also a greater freedom from the mechanical, thermal, and magnetic changes to which, notwithstanding all precautions to the contrary, a crowded laboratory, situated in the midst of a large city, is constantly exposed.

In a recent paper, ${ }^{2}$ Professor Merritt has shown that the first

1 The scale was removed from the telescope and placed about $3 \mathrm{~m}$. from the bolometer, from which it was separated by a cardboard screen.

${ }^{2}$ Merritt, Am. Journal of Science (3), 4I, p. 422, I89I. 
throw of a galvanometer, when used with a thermopile or a bolometer, bears a constant ratio to the final deflection, and is therefore proportional to the heat radiated.

At each position throughout the spectrum the energy was measured by two such observations and the mean taken.

III. THE SPECTRUM OF THE EIECTRIC ARC.

Many vain attempts were made to detect traces of lines in the infra-red spectra of the alkalies when these metals were burned in a Bunsen burner or in the oxyhydrogen flame. Not until the electric arc was used for this purpose did efforts in this direction meet with success.

Inasmuch as it was suspected that a number of the observed infra-red spectral lines owed their origin to the arc itself and not to the metals therein consumed, it seemed all important to postpone the study of metallic spectra until a careful investigation of the distribution of energy in the infra-red spectrum of the electric arc had been made.

As a means of producing the arc an old Duboscq lamp was used, which, when supplied with current from the constant potential mains of the Berlin Central Station (I Io volts), burned very quietly. By introducing resistance the current through the lamp was maintained constant at from 7.5 to 7.8 ampères.

After many experiments with carbons of various sizes, it was found that more perfect uniformity in the length of the arc $\left(6 \frac{1}{2} \mathrm{~mm}\right.$.), together with greater quietness and regularity of burning, were secured by using carbons $8 \mathrm{~mm}$. in diameter. The arc exhibited also less of a tendency to wander when a cored carbon was used as the anode.

By means of a lens, a real image of the arc, enlarged about twofold, was projected upon the slit of the spectrometer. Immediately before the slit was placed a large screen in such a way that the images of the incandescent carbons, as well as the lateral portions of the arc itself, were intercepted, and only a small strip, $7 \mathrm{~mm}$. long and exceedingly narrow, belonging to 
the central region of the projected arc, was allowed to enter the collimating tube of the instrument.

In the entire series of measurements which follow, the opening of the slit did not exceed .I mm. in width, and subtended an angle in the spectrum of 1.68 minutes. The width of the slit had been adjusted until its image in the telescope was just superposed upon the thread of the bolometer with its lamp-black coating.

Although the strength of the current in the Wheatstone's bridge was maintained as nearly constant as possible at $\frac{1}{40}$ ampère, yet before each series of observations the sensitiveness of the apparatus to temperature was determined according to the method already described, so that the results of the different determinations could be compared.

The energy was always assumed to be proportional to the deflection of the galvanometer needle. This assumption, however, is justified by the papers of Angström, ${ }^{1}$ Rubens, ${ }^{2}$ and Merritt. ${ }^{3}$

In the manner already described, a large number of observations were conducted in order to determine the character of the spectrum of the arc light. The almost perfect agreement of the results obtained makes it a matter of indifference which particular series is selected from the material at hand to be given here in all its details.

The data are given with greater completeness in the following table than in the subsequent measurements, from the fact that the same order of procedure was followed throughout the entire investigation, and in the description of the distribution of energy in metallic spectra, to be given later, reference will be made to this series for many minor points.

The first column contains the angular deviations of the arm of the bolometer as read on the circle of the spectrometer, and the second contains the corresponding wave-lengths, determined with the aid of the curve of dispersion, Fig. 2, Plate I. In the third column are found the means of the galvanometer deflections,

1 Angström, Wied. Ann., 26, p. 262, I885.

2 Rubens, Wied. Ann., 37, p. 256, 1889.

3 Merritt, Am. Journal (3), 37, p. 167, 1889. Merritt, Am. Journal (3), 41, p. 422, $189 \mathrm{~s}$. 
which were taken in the manner described above, and which were used without further correction as the relative values of the energy measured. (See Table III. on pages 45 and 46.)

Sensitiveness of the Apparatus to Temperature. - Deflections: I 28, I 35, I 28, I 32, I32, I 34. Mean : I 32.

$$
a=\frac{\mathrm{I} 36+\mathrm{I} 32}{2}=\mathrm{I} 34
$$

Wherefore

$$
k=\frac{1}{134000^{\circ}}{ }^{\circ} \text {. }
$$

The data contained in this table are graphically represented in the curve Fig. 3, Plate I. Angular deviations of the arm of the bolometer are chosen as abscissa, and corresponding deflections in millimeters as ordinates.

In order that the positions of the maxima and minima of this curve may be more easily recognised, a number of Fraunhofer lines are drawn for comparison. The limits of the visible spectrum, as ordinarily accepted, are indicated by dotted lines. The assignment of these limits is naturally attended by much uncertainty, since the investigations of Helmholtz, ${ }^{1}$ Esselbach, ${ }^{2}$ Becquerel, ${ }^{3}$ and Langley ${ }^{4}$ have shown that under peculiarly favorable conditions the eye can perceive radiations, the wavelengths of which lie far beyond these boundaries. The present paper also contains facts tending to confirm these statements.

In Fig. 4, Plate I., the same curve is represented, with the single exception that wave-lengths are chosen as abscissæ instead of divisions on the circle.

A glance at these curves shows at once the remarkable fact that in the spectrum of the electric arc, the maximum of the energy lies farther in the direction of the short wave-lengths than the Fraunhofer lines $H$ and $K$.

The principal maximum of the energy curve extends from

${ }^{1}$ Helmholtz, Pogg. Ann., 94, p. I2, 1855.

2 Esselbach, Monatsber. d. k. Acad. d. Wiss. zu Berlin, p. 757, 1855; Esselbach, Pogg. Ann., 98, p. 514, I856.

${ }^{3}$ H. Becquerel, Compt. Rend., 97, p. 73, 1883.

4 I.angley, Phil. Mag. (5), 21, p. 396, 1886. 
No. I.] THE INFRA-RED SPECTRA OF THE ALKALIES.

TABLE III.

ELECTRIC ARC.

Sensitiveness of the Apparatus to Temperature. Deflection in Millimeters: 137, 138, 138, 130, 136. Mean: 136.

Observations of Energy.

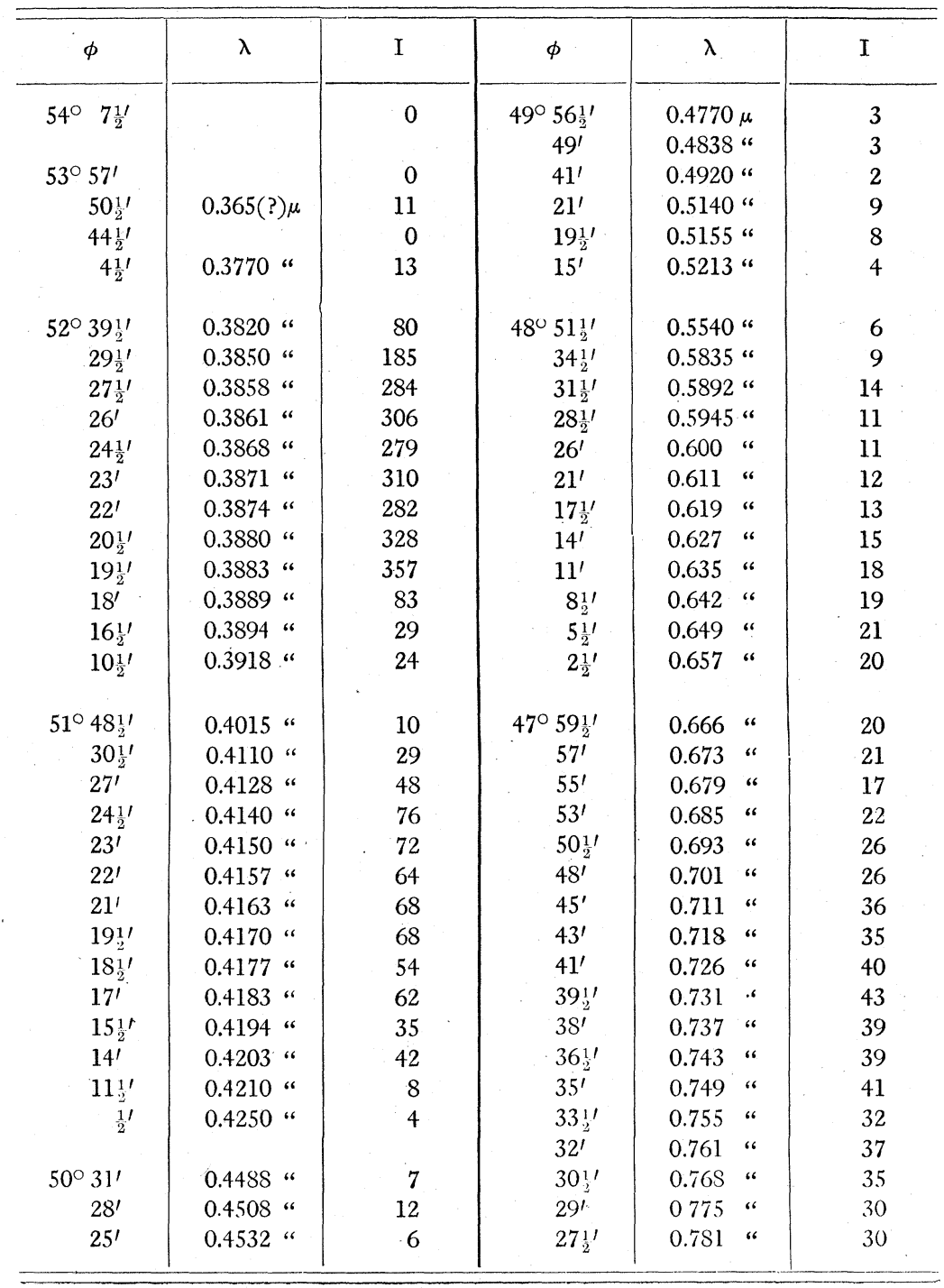


TABLE III. - Continued.

\begin{tabular}{|c|c|c|c|c|c|}
\hline$\phi$ & $\lambda$ & I & $\phi$ & $\lambda$ & I \\
\hline $47^{\circ} 26^{\prime}$ & $0.788 \mu$ & 50 & $46^{\circ} 25^{\prime}$ & $1.276 \mu$ & 12 \\
\hline $24 \frac{1}{2}{ }^{\prime}$ & 0.794 “ & 57 & $23 \frac{11}{2}$ & 1.295 “ & 8 \\
\hline $23^{\prime}$ & 0.801 “ & 62 & $22^{i}$ & 1.312 “ & 5 \\
\hline $21 \frac{1}{2}^{\prime}$ & 0.808 “ & 74 & $202^{\prime \prime}$ & 1.330 “ & 5 \\
\hline $20^{\prime}$ & 0.815 “ & 68 & $19^{\prime}$ & 1.352 “ & 8 \\
\hline $18 \frac{1}{2}$ & 0.823 “ & 66 & $177^{1}$ & 1.372 “ & 13 \\
\hline $17^{i}$ & 0.830 “ & 65 & $16^{i}$ & 1.392 “ & 21 \\
\hline $15 \frac{1^{\prime}}{\prime}$ & 0.838 “ & 54 & $14 \frac{1}{2} \prime$ & 1.413 “ & 24 \\
\hline $14^{\prime}$ & 0.846 “ & 51 & $13^{\prime}$ & 1.435 “ & 24 \\
\hline $12 \frac{1^{\prime}}{\prime}$ & 0.854 “ & 44 & $11 \frac{1}{2}^{\prime}$ & 1.453 “ & 24 \\
\hline $10_{2}^{\prime \prime}$ & 0.865 “ & 33 & $92^{\prime \prime}$ & 1.482 “ & 21 \\
\hline $9^{\prime}$ & 0.875 “ & 30 & $8^{i}$ & 1.502 “ & 14 \\
\hline $72^{1 \prime}$ & 0.886 “ & 26 & $6 \frac{1}{2}^{\prime}$ & 1.523 “ & 11 \\
\hline $6^{\prime}$ & 0.896 “ & 23 & $5^{\prime}$ & 1.543 “ & 10 \\
\hline $4 \frac{1{ }^{\prime}}{2}$ & 0.906 “ & 60 & $3 \frac{1}{2}^{\prime}$ & 1.563 “ & 8 \\
\hline $3^{\prime}$ & 0.917 “ & 98 & $2^{i}$ & 1.583 “ & 9 \\
\hline $1 \frac{1{ }^{\prime}}{2}$ & 0.928 “ & 95 & $\frac{1^{\prime}}{2}$ & 1.603 “ & 6 \\
\hline \multirow[t]{2}{*}{$0^{\prime}$} & 0.940 “ & 97 & & & \\
\hline & & & $45^{\circ} 59^{\prime}$ & 1.626 “ & 4 \\
\hline $46^{\circ} 58 \frac{1}{2}^{\prime}$ & 0.951 “ & 86 & $57 \frac{1}{2}^{\prime}$ & 1.645 “ & 3 \\
\hline $57^{\prime}$ & 0.962 “ & 67 & $56^{\prime}$ & 1.665 “ & 2 \\
\hline $55_{2}^{\prime \prime}$ & 0.974 “ & 57 & $54 \frac{1}{2}$ & 1.685 “ & 2 \\
\hline $54^{\prime}$ & 0.987 “ & 48 & $53^{\prime}$ & 1.705 “ & 2 \\
\hline $522_{2}^{\prime \prime}$ & “ & 36 & $511^{\frac{1}{2}}$ & 1.725 “ & 0 \\
\hline $51^{\prime}$ & 1.012 “ & 29 & $50^{\prime}$ & 1.747 “ & 0 \\
\hline $499_{2}^{\prime \prime}$ & 1.024 “ & 24 & $482^{1 \prime}$ & 1.769 “ & 1 \\
\hline $48^{i}$ & 1.038 “ & 18 & $47^{\prime}$ & 1.789 “ & 0 \\
\hline $46 \frac{1}{2}{ }^{\prime}$ & 1.050 “ & 16 & $45 \frac{1}{2}^{\prime}$ & 1.810 “ & 0 \\
\hline $44 \frac{1}{2^{\prime}}$ & 1.068 “ & 16 & $44^{\prime}$ & 1.830 “ & 0 \\
\hline $43^{\prime}$ & 1.082 “ & 75 & $42 \frac{1}{2}^{\prime}$ & 1.850 “ & 0 \\
\hline $412^{\prime \prime}$ & 1.096 “ & 103 & $41^{\prime}$ & 1.870 “ & 0 \\
\hline $40^{\prime}$ & 1.109 “ & 80 & $39^{\prime}$ & 1.897 “ & 0 \\
\hline $38_{2}^{\prime \prime}$ & 1.128 “ & 59 & $37 \frac{1}{2}^{\prime}$ & 1.918 “ & 0 \\
\hline $37^{\prime}$ & 1.144 “ & 47 & $36^{\prime}$ & 1.938 “ & 0 \\
\hline $35 \frac{1}{2} \prime$ & 1.158 “ & 35 & $342^{\frac{1}{2}}$ & 1.958 “ & 0 \\
\hline $34^{\prime}$ & 1.176 “ & 29 & $33^{\prime}$ & 1.978 “ & 0 \\
\hline $32 z^{\prime}$ & 1.192 “ & 26 & $31_{2}^{1 \prime}$ & 2.000 “ & 0 \\
\hline $31^{i}$ & 1.208 “ & 23 & $30^{\prime}$ & 2.020 “ & 0 \\
\hline $299^{\prime \prime}$ & 1.225 “ & 17 & $282^{11}$ & 2.042 “ & 0 \\
\hline $28^{\prime}$ & 1.243 “ & 18 & $27^{\prime}$ & 2.062 “ & 0 \\
\hline $26 \frac{1}{2}^{\prime}$ & 1.258 “ & 13 & & & \\
\hline
\end{tabular}


$\lambda=.385 \mu$ to $\lambda=.388 \mu$; a secondary maximum is comprised within the region between $\lambda=.4$ I I $\mu$ and $\lambda=.420 \mu$.

In examining these exceedingly intense bands with the eye, it was found that the first consisted of five narrower bands, and the second of six, all of which were sharply defined on the side looking toward the red end of the spectrum, but which grew rapidly indistinct and haźy in the opposite direction.

A peculiarity of the arc spectrum was observed in this connection which, as was found later, had also been noticed by Kayser and Runge, ${ }^{1}$ viz.: that when the slit of the spectroscope is made very narrow, the entire spectrum of the electric arc consists of many thousand fine lines which lie exceedingly close together at those places where the bright bands are visible, and are arranged at slightly greater intervals in the other portions of the spectrum.

With the bolometer, in the form in which it was used, it was not possible to detect these individual lines, which are often not more than a second of arc apart. Only a summation could be obtained which represents an integral of all the smaller portions of energy which fell upon the filament of the bolometer, I.6 minutes of arc in width. The energy in the arc spectrum was accordingly measured with a breadth of slit approximately equal to the width of the sensitive bolometer thread. What was then observed was the characteristic banded spectrum, formed by a partial overlapping of this large number of fine lines.

Shortly before the close of the entire investigation, there was detected, first optically and then with the aid of the bolometer, a feeble band which lies still farther in the direction of the extreme violet than the group from $\lambda=.385 \mu$ to $\lambda=.388 \mu$. By an extensive extrapolation of the curve of dispersion an approximate wave-length, $\lambda=.365 \mu$, was ascribed to this band, but this value, it must be remembered, lays no claim to being correct. Without doubt this band is identical with the one found by Kayser and Runge ${ }^{2}$ to lie from $\lambda=.3584 \mu$ to $\lambda=.3590 \mu$.

In their spectrophotometric comparison of the various sources

1 Kayser und Runge, Wied. Ann., 38, p. 81, 1889.

${ }^{2}$ Kayser und Runge, Wied. Ann., 38, p. 90, 1889. 
of illumination, Nichols and Franklin ${ }^{1}$ have described a band in the spectrum of the electric light, which can be easily identified with the series of bands from $\lambda=.4$ IIO $\mu$ to $\lambda=.42$ IO $\mu$; for, although representing far less energy than the group between $\lambda=.385 \mu$ and $\lambda=.388 \mu$, the former are optically much brighter than the latter. It is also to be noticed that the limits for the wave-length of this band, as given by Nichols and Franklin, lie nearer the group between $\lambda=.4 \mathrm{I}$ Iо $\mu$ and $\lambda=.42$ Iо $\mu$.

In a recent paper, $\mathrm{P}$. Drude and W. Nernst ${ }^{2}$ mention two bands in the spectrum of the arc light which excite a peculiarly active fluorescent effect upon a solution of fluorescene. They determined the wave-lengths of these bands with the aid of a diffraction grating, and obtained for the more refrangible and at the same time optically weaker band the value $\lambda=.386 \mu$. This determination coincides so closely with the values found in the present paper for bands in this region as to leave no doubt as to the identity of those bands with the ones here investigated.

The energy throughout the remaining portions of the visible spectrum of the electric arc, as compared with the unusually large amount to be found in the violet, is quite unimportant. A small quantity of a sodium salt, always present as an impurity in the carbons, may be detected by the appearance of several of the characteristic sodium lines. The stronger of these, especially the D-lines, may be measured with the bolometer. In the visible spectrum are found, moreover, several indistinct bands which, on account of their feeble energy, are hardly to be distinguished from the bright background, and therefore are scarcely to be recognized in the figure. Not until the region of the infra-red is reached are well-developed maxima and minima again found, and here the bolometer detects five intensely warm bands, similar in many respects to those in the extreme violet, but showing, on the other hand, the noticeable difference that their sharply defined edges are turned toward the visible portion of the spectrum, while an indistinct border bounds each of these bands

1 Nichols and Franklin, Am. Journal (3), 38, p. 106, 1889.

2 Drude und Nernst, Wied. Ann., 45, p. 460, 1892. 
on the side of the longer wave-lengths. In all probability these bands consist of a warm background upon which is superposed a series of lines more or less sharply defined. The dispersion of the prism employed was, however, too feeble to permit of a complete separation of these lines by the bolometer. Their presence was nevertheless detected by the small irregularities which the curve shows in the neighborhood of each of the five maxima.

The wave-lengths of these five infra-red bands are as follows:-

TABLE IV.

$$
\begin{aligned}
& A \text {. from } \lambda=0.700 \mu \text { to } \lambda=0.770 \mu \\
& \text { B. " " } \lambda=0.785 \text { “ “ } \lambda=0.860 \text { “ } \\
& \text { C. " " } \lambda=0.900 \text { “ " } \lambda=1.000 \text { “ } \\
& \text { D. “ } \lambda=1.075 \text { " " } \lambda=1.160 \text { “ } \\
& \text { E. “ } \lambda=1.370 \text { “ " } \lambda=1.500 \text { “ }
\end{aligned}
$$

IV. ON THE GRAPHICAL REPRESENTATION OF THE DISTRIBUTION OF ENERGY THROUGHOUT THE SPECTRUM.

In general it is not possible, in transforming to the normal spectrum the distribution of energy as observed by means of a prism, to retain in their original lengths the ordinates which in the diffraction spectrum represent the energy throughout the region measured. At each point of the curve, the lengths of the new ordinates must be so chosen that the curves (see Fig. 7), bounded by the wave-lengths $\lambda$ and $\lambda^{\prime}$ and comprised between the interval $\left(\lambda-\lambda^{\prime}\right)$ on the axis of abscissæ and the portion of the

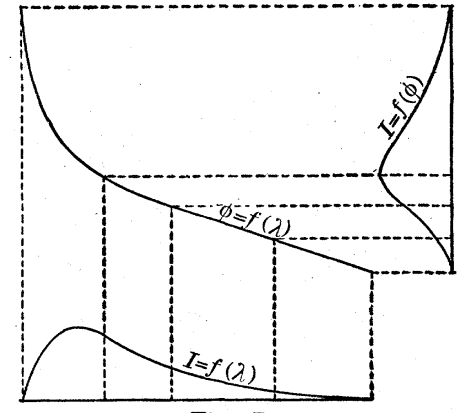

Fig. 7. curve immediately above, must, both in dispersion and diffraction spectrum, be equal.

Professor Langley has suggested ${ }^{1}$ a simple means of accomplishing this purpose, and illustrates his method by a drawing from which the idea of the accompanying figure has been taken.

1 Langley, A Report of the Mt. Whitney Expedition, p. 231, I884. Phil. Mag. (5), I7. p. 211,1884 . 
While this method serves to transform to the normal a continuous prismatic spectrum, it fails in its application to a bright line or discontinuous spectrum. In the latter case the width of the lines, so long as these do not overlap, is entirely independent of the amount of dispersion produced by the prism, and the reduction to the normal spectrum can be made without changing the lengths of the ordinates.

With the aid of a micrometer eye-piece it was determined that the width of the sharp spectral lines, for the amount of dispersion used in these determinations, was the same throughout all regions of the visible spectrum. Nevertheless, it was obviously impossible to consider the distribution of energy, shown in Fig. 4, Plate I, as the distribution in the normal spectrum, inasmuch as the lines, of which the entire series of bands consists, to a greater or less extent overlap. Moreover, the spectrum, strictly speaking, is not a continuous one, and therefore the reduction, as given by Langley, cannot be here applied. In the delineation of the energy contained in the radiations from the electric arc as well as in that of the metals to be later described, the author has been compelled to use as ordinates the values obtained from the dispersion spectrum, and to plot wave-lengths as abscissæ instead of angular deviations.

Mention must be made at this point, however, of the fact that if the assumption be made that the spectrum of the electric arc is a continuous one, in the sense in which the spectrum of an incandescent solid is so considered, the violet bands at $\lambda=.388 \mu$ and $\lambda=.4 \mathrm{I} 5 \mu$ would be many times more intense, as compared with the energy in the infra-red bands, than appears in the drawing, Fig. 4, Plate I. 